\title{
Familial incidence of juvenile diabetes mellitus, progressive optic atrophy, and neurogenic deafness
}

\author{
P. R. STEVENS AND W. A. L. MAGFADYEN \\ Royal Infirmary, Blackburn, Lancs.
}

Wolfram (1938) published a report from the Mayo Clinic concerning the incidence of diabetes mellitus and optic atrophy in four siblings. He commented that "an aetiological\& relationship between diabetes mellitus and simple progressive optic atrophy is by no means은 well established". During the ensuing years other families have been described, members of which have shown a similar association between juvenile diabetes mellitus and progressive optic atrophy (Tyrer, I943; Stansbury, I948; Tunbridge and Paley, r 956; Walsh, $1957{ }_{-}^{\circledR}$ Shaw and Duncan, 1958; Barjon, Labauge, Cazaban, and Fabre, 1963; Rose, Fraser, Friedman, and Kohner, I966; Rorsman and Söderström, I967), suggesting that the relationship between the two is due to more than chance. Indeed, Rose and otherso (1966) and Rorsman and Söderström (1967) expressed the view that an autosomal recessive mode of inheritance was likely.

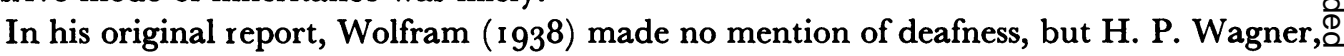
in a personal communication to Tunbridge and Paley (1956), stated that "three of Wolfram's patients had subnormal hearing". Tyrer (1943) and Stansbury (1948) did not state whether their patients were deaf, but Tunbridge and Paley (1956), Shaw and Duncan (1958), Barjon and others (1963), and Rose and others (1966) reported bilateral nerve deafness in twelve out of fourteen cases.

Until now only 29 cases in fourteen families have been recorded. The present report concerns another family, two members of which exhibit this uncommon syndrome.

\section{Case reports}

The cases reported are two siblings of a family of six. None of their brothers or sisters hado diabetes mellitus or optic atrophy, and neither their parents (Figure) nor other relatives for three generations past have been known to have had diabetes mellitus or defective vision.

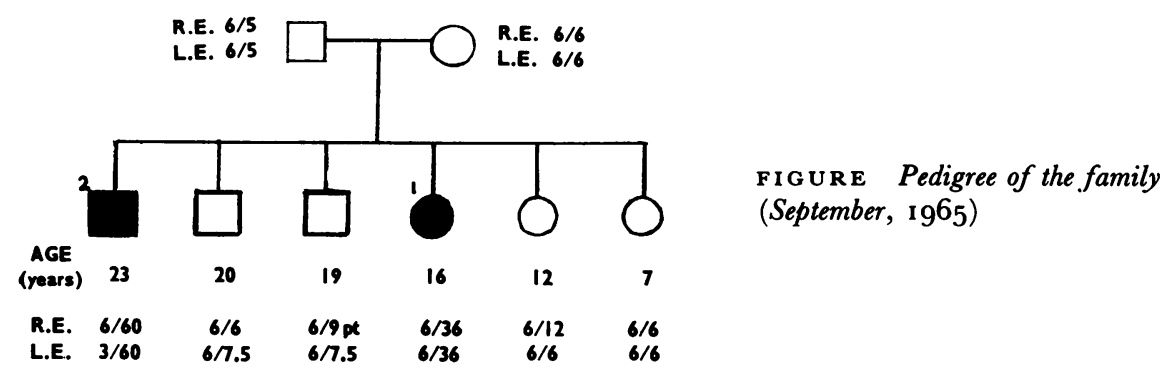


Case 1, a girl now aged 22 years, was referred to the Ophthalmic Department during September, 1965 , with a history of progressive loss of vision of each eye. She was then 16 years of age and had been a known diabetic for the previous 5 years. (Her eldest brother is also a diabetic (Case 2) and their mother had been in the habit of testing the urine of all her children at regular intervals.) At first dietary control was sufficient but within 12 months of onset she had persistent glycosuria and soluble insulin was added to her treatment. In August, 1965, her therapy was changed to Rapitard Insulin and Ultra-Lente Insulin and her diabetic state has remained fairly stable since then apart from one episode of hyperglycaemia associated with a severe upper respiratory infection. Her progressive loss of vision appeared to be synchronous with the progress of the diabetes mellitus. She had no other past history of ocular disease or injury.

\section{Examination}

The fundi revealed well-established optic atrophy. There were no signs of diabetic retinopathy and the fundi were otherwise normal. The corrected visual acuity was $6 / 36$ in each eye. The peripheral visual field of the right eye was normal, and that of the left eye showed a slight concentric contraction. Colour vision was defective and was of the "acquired type" (Kalmus, 1965). Audiography showed a bilateral high-tone nerve loss of hearing after 4,000 cycles per second. No other neurological defects were found.

Investigations Wassermann reaction: negative.

$X$-ray of the skull showed normal optic foramina and pituitary fossa.

Blood urea: $20 \mathrm{mg} . / 100 \mathrm{ml}$.

Serum B. 12 : $100 \mu \mathrm{g}$./100 ml.

Thyroid auto-precipitin test: negative.

Thyrotoxic (antimicrosomal) complement-fixation test: negative I in 5 .

Tanned cell agglutinating antithyroglobulin titre: negative $I$ in $I 0$.

Chromosome pattern: normal.

Progress

Her sight has deteriorated slowly and in October, 1969, the visual acuity was $4 / 60$ in the right eye and $3 / 60$ in the left. A telescopic spectacle (Hamblin Emmetropic Unit with distance addition) improved her visual acuity to $6 / 18$ with each eye, and $N_{5}$ with the near addition. However, she is reluctant to use these aids in public and they are only rarely used even in the privacy of her home.

Examination of the fundi in October, 1969 , revealed a solitary small retinal haemorrhage between the macula and optic disc of the right eye. No further retinal changes have been observed to the present and her vision has not changed any further. No other manifestations of neurological involvement have appeared.

Case 2, a young man now aged 29, was diagnosed as diabetic when he was 15 years old. He was a small, thin boy who had hitherto enjoyed good health. His diabetic condition was stabilized on 16 units of Lente Insulin each day and a 16 line Lawrence diet. All went well for a time but in April, 1959, unknown to his parents, he stopped taking insulin on the advice of an uninitiated lay person. He felt well and ate indiscriminately. In consequence his health deteriorated and he was admitted to hospital for stabilization in December, 1959, after which his diabetic state has remained fairly stable.

During his 18 th year he became aware of progressive deterioration in his visual acuity. He was found to have a simple myopic error of refraction (right eye $-2.5 \mathrm{D} \mathrm{sph}$.; left eye $-4 \mathrm{D} \mathrm{sph}$.) and glasses were prescribed, but his sight continued to fail. He attended the Ophthalmic Department after his sister's optic atrophy had been discovered and was found to be similarly affected.

\section{Examination}

The fundi revealed bilateral primary optic atrophy. There was no evidence of a diabetic retinopathy or a peripheral retinal degeneration. The spectacle refraction was correct and his visual acuity 


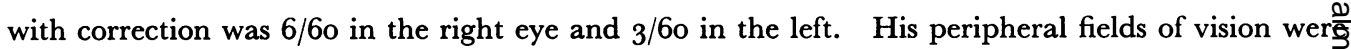
slightly contracted in each nasal hemisphere and his colour vision was grossly defective.

Audiography showed a slight high-tone nerve loss affecting principally the left ear. There wer no other signs of neurological abnormality.

Investigations Blood urea: $30 \mathrm{mg} . / 100 \mathrm{ml}$.

Serum B.12: $110 \mu \mathrm{g} . / 100 \mathrm{ml}$.

Wassermann reaction: negative.

Thyroid autoprecipitin test: negative.

Thyrotoxic (antimicrosomal) complement-fixation test: negative $\mathrm{I}$ in 5 .

Tanned cell agglutinating antithyroglobulin titre: negative $\mathrm{I}$ in $\mathbf{I}$.

Chromosome pattern: normal.

\section{Progress}

The visual acuity has not altered significantly and when checked in October, 1969, was 6/60 in the right eye and $4 / 60$ in the left. He had some difficulty in adjusting to his partial sight but eventuall he trained as a computer programmer and obtained employment in Newcastle.

\section{Discussion}

The importance of recording all the initial cases of a familial syndrome complex lies in the need to establish the pattern of the disease process coupled with the assessment of the probo ability of its transmission to succeeding generations. Including our own, 3 I cases have now been described and the pattern of the syndrome of juvenile diabetes mellitus, progressivg optic atrophy, and neurogenic deafness is becoming apparent.

These 31 reported cases have occurred in fifteen families, five of the patients wert childre $\vec{B}$ of consanguineous first cousin marriages, and nine families have more than one affected sibling, The onset of the diabetes mellitus occurred between the ages of 2 and 18 years the greater number (2 I out of $3 \mathrm{I}$ ) occurred before the age of I I years. The sexes were almost equally affected, seventeen patients being male and fourteen female. The age aథ onset of the optic atrophy in the 27 cases in which it was known, was between the ages of 2 and 24 years; in the majority (23 cases out of 27 ) the optic atrophy occurred before the age of 16 years. Four patients had a late onset of optic atrophy at 18 (2 cases), I 9 , and 2 皮 years of age respectively. In only five cases did the optic atrophy antedate the onset of the diabetes mellitus, and in one patient (Case I, described above) the optic atrophy prop gressed synchronously with the diabetes mellitus. The onset of optic atrophy after the onset of diabetes was fairly evenly distributed over a 12-year period (from 4 to I 5 years of age) in the remaining seventeen cases. The vision in some cases deteriorated to remarkably low level, but only in one instance to the point of total blindness.

At first it was not appreciated that deafness had any part in the syndrome, and Tunbridge and Paley (1956) were the first to draw attention to this feature. They also reported that Wagner had re-examined Wolfram's patients and found that three of them had "subnormas hearing as tested for a watch tick". Their own two cases each had an audiograph showingo complete absence of bone conduction to all frequencies. Four cases had subnorma hearing of sufficient severity for it to have been appreciated by the patients, indeed on child was so severely affected as to require education for a time at a school for the dea $\$$ before his transfer to a school for the partially-sighted (Rose and others, 1966). The remaining seven cases of hearing loss appear to have been discovered by audiography 
The deafness appears to commence as a high frequency loss of which the patient is seemingly unaware. Thus it is not possible to date the time of onset of the deafness in relation to the onset of the diabetes mellitus in the majority of cases and the only conclusion that can be drawn is the generalization that the diabetes probably appeared first. In only two cases is it certain that deafness antedated the onset of the diabetes (Shaw and Duncan, 1958).

Five patients showed a pigment disturbance of the fundus. A fine granular dispersion at the posterior pole lessening towards the periphery with abnormal electroretinograms is reported by Rose and others (1966) in two of their cases. Rorsman and Söderström ( 1967 ) reported a fine granular pigment dispersion at the macula of three of their cases together with scattered pigment accumulations at the periphery of the retina. Electroretinogram examinations were not carried out on their patients. Alström, Hallgren, Nilsson, and Åsander (1959) described a syndrome in three members of two inter-related families which they suggest is a variant of the Lawrence-Moon-Biedl syndrome, consisting of atypical retinal degeneration, loss of central vision, obesity, diabetes mellitus, and neurogenic deafness. Heycock and Wilson (1958) reported a case of juvenile diabetes mellitus in Refsum's syndrome in which atypical retinitis pigmentosa and deafness are features.

A variety of other defects have been recorded:

Diabetic retinopathy, 3 cases.

Pulmonary tuberculosis, 2 cases.

Obesity, infantilism, and atypical Friedreich's ataxia, I case.

Cortical atrophy and intellectual deterioration, I case.

Poliomyelitis, I case.

Epilepsy, 2 cases.

Myelopathy (cord bladder), 3 cases.

Sideroblastic anaemia, I case.

"Diabetic" cataract, I case.

Congenital cataract, I case.

Posterior cortical cataract, I case.

Simple goitre and infantilism, I case.

Juvenile diabetes mellitus and optic atrophy have also been described in association with diabetes insipidus (Raiti, Plotkin, and Newns, I963; DeLawter, I949; and Casa, I955) and with Friedreich's ataxia (Schlezinger and Goldstein, r940; Dewar, 1953; Podolsky, Pothier, and Krall, I964; Darnaud, Plauchu, Denard, Dalmais, Bertrand, and Sterlin, I964).

A steroid provocative test for incipient diabetes mellitus was carried out on the parents of the two cases reported and was negative in each instance. The appearance then of two cases of this syndrome in a family of six siblings with clinically normal parents would support the view that it has an autosomal recessive mode of inheritance.

\section{Summary}

Two further cases of the syndrome of juvenile diabetes mellitus, progressive optic atrophy, and neurogenic deafness are described. The literature is reviewed and the syndrome discussed in terms of the 31 recorded cases.

Our thanks are due to the Department of Medical Illustration, Manchester University, for help in the preparation of the Figure. 


\section{References}

Alström, G. H., hallgren, B., Nilsson, c. B., and Åsander, H. (1959) Acta psychiat. scand., 34,

Suppl. 129

barjon, P., Labauge, R., Cazaban, R., and fabre, s. (1963) Diabète, Ix, 331

CASA, D. (1955) Acta genet. med. (Roma), 4, 230

Darnaud, C., Plauchu, M., Denard, Y., Dalmais, J., Bertrand, J., and sterlin, M. (1964) Diabete,

12, 189

Delawter, D. E. (1949) Med. Ann. D.C., 18, 398

DEWAR, H. A. Quoted by ASHBY, D. W., and TWEEDY, P. s. (1953) Brit. med. F., 1, 1418

HEYCOCK, J. B., and wiLson, J. (1958) Arch. Dis. Childh., 33, 320

Kalmus, H. (1965) "Diagnosis and Genetics of Defective Colour Vision", p. I4. Pergamon Press

Oxford

PODOLSKy, S., POThIER, A., and KRALl, L. P. (1964) Arch. intern. Med., 1r4, 533

RAITI, S., PLOTKIn, s., and NeWNs, G. H. (1963) Brit. med. F., 2, 1625

RORSMAN, G., and SÖDERSTRÖM, N. (1967) Acta med. scand., 182, $4^{19}$

ROSE, F. C., FRASER, G. R., FRIEDMANN, A. I., and KOHNER, E. M. (I966) Quart. J. Med., 35, 385

SGHLEZINGER, N. s., and Goldstein, K. (1940) N.Y. St. F. Med., 40, 415

Shaw, D. A., and duncan, L. J. P. (1958) F. Neurol. Neurosurg. Psychiat., 21, 47

stansbury, J. R. (1948) Amer. F. Ophthal., 31, I 153

TUNBRIDGe, R. E., and PALEY, R. G. (1956) Diabetes, 5, 295

tyrer, J. (1943) Med. F. Aust., 2, 398

WALsh, F. B. (1957) “Clinical Neuro-Ophthalmology", 2nd ed., p. 707. Williams and Wilkins N

Baltimore

wolfram, D. J. (1938) Proc. Mayo Clin., 13, 715 